\title{
ANÁLISE MICROBIOLÓGICA E IDENTIFICAÇÃO DE ADULTERANTES EM LEITE IN NATURA E PASTEURIZADO COMERCIALIZADO EM JEQUIÉ-BA
}

\author{
MICROBIOLOGICAL ANALYSIS AND IDENTIFICATION OF ADULTERANTS IN \\ NATURA AND PASTEURIZED MILK COMMERCIALIZED IN JEQUIÉ-BA
}

\author{
lara Pereira dos Santos' \\ Tauá Alves Melo² \\ Fernanda Maria Oliveira Sousa ${ }^{3}$
}

\section{RESUMO}

O leite é um dos alimentos mais consumidos no Brasil, gerando constante preocupação com sua qualidade. Devido ao alto valor nutritivo, é um meio propício a proliferação de micro-organismos, inclusive aqueles patogênicos aos seres humanos. Este trabalho teve como objetivo verificar a presença de substâncias adulterantes e analisar a qualidade microbiológica de leite cru e pasteurizado quanto à presença de coliformes termotolerantes e Salmonella. 12 amostras foram coletadas na qualidade de consumidor diretamente de vendedores que comercializam informalmente o leite in natura e de supermercados em diferentes pontos do município de Jequié- BA. Para a pesquisa microbiológica foi utilizada a técnica de tubos múltiplos seguindo a instrução normativa n 62 de 2003. As análises quanto à adulteração buscaram a presença de reconstituintes de densidade, agentes neutralizantes e inibidores de crescimento. Todos os protocolos seguiram a IN 68 de 2006. Em relação à pesquisa de adulterantes somente na prova de cloretos as amostras analisadas não apresentaram resultados satisfatórios de acordo o preconizado pela IN 76 de 2018. Na pesquisa por Salmonella spp. 25\% das amostras analisadas obtiveram resultado positivo que foi confirmado através de provas bioquímicas. Das análises quanto à contaminação por coliformes termotolerantes, 66,6\% não se encontravam dentro dos padrões estabelecidos pela RDC n ${ }^{\circ} 12$ de 2001, com resultados que variaram de 4,3 a >110 NMP/mL. Os resultados revelaram que algumas amostras não estão de acordo os padrões estabelecidos por lei, demonstrando a importância dos cuidados higiênico-sanitários no processo de produção e venda do leite, reforçando a importância dos tratamentos térmicos no controle da qualidade microbiológica.

Palavras-chave: Contaminação microbiológica. Adulterantes. Leite cru.

1 Graduanda em Biomedicina pela Faculdade de Tecnologia e Ciências (FTC). E-mail: iara.pereira.11@hotmail.com 2 Doutor em Biologia e Biotecnologia de Microrganismos pela Universidade Estadual de Santa Cruz (UESC). Docente da Faculdade de Tecnologia e Ciências (FTC). E-mail: tauamelo@yahoo.com.br

3 Doutora em Biologia e Biotecnologia de Microrganismos pela Universidade Estadual de Santa Cruz (UESC). Docente da Faculdade de Tecnologia e Ciências (FTC). E-mail: fernandamosousa@yahoo.com.br

\section{INTER/SCIENTIA}

REVISTA INTERSCIENTIA | V. 7 | N. 1 | P. 66-82 | JAN-JUN/2019 


\section{ABSTRACT}

Milk is one of the most consumed foods in Brazil, generating constant concern for its quality. Due to the high nutritive value, it is a means conducive to the proliferation of microorganisms, including those pathogenic to humans. This study aimed to verify the presence of adulterating substances and to analyze the microbiological quality of raw and pasteurized milk in relation to the presence of Thermotolerant coliforms and Salmonella. 12 samples were collected in the consumer quality directly from sellers who informally commercialize milk in Natura and supermarkets in different points of the municipality of Jequié-BA. For microbiological research, we used the multiple tube technique following normative instruction $N^{\circ} 62$ of 2003 . The analysis of the adulteration sought the presence of density reconstituents, neutralizing agents and growth inhibitors. All protocols followed the IN 68 of 2006. In relation to the investigation of Adulterants only in the chlorides test, the samples analyzed did not present satisfactory results according to the recommended by the IN 76 of 2018. In the survey by Salmonella spp. $25 \%$ of the analyzed samples obtained positive results that were confirmed by biochemical tests. From the analyses regarding contamination by thermotolerant coliforms, $66.6 \%$ were not within the standards established by RDC No. 12 of 2001, with results ranging from 4.3 to $>110 \mathrm{NMP} / \mathrm{mL}$. The results revealed that some samples do not conform to the standards established by law, demonstrating the importance of hygienic-sanitary care in the process of production and sale of milk, reinforcing the importance of thermal treatments in Microbiological quality control.

Keywords: Microbiological contamination. Adulterants. Raw milk.

\section{INTRODUÇÃO}

O leite é um dos alimentos mais consumidos no Brasil, principalmente por crianças e idosos. Assim, há uma constante preocupação com sua qualidade, tanto pelos profissionais da área de saúde quanto de laticínios. Sabendo-se da relevância desse alimento na nutrição dos seres humanos, fica evidente o porquê é tão importante averiguar a presença de adulterantes ou contaminação microbiológica que podem não só diminuir a qualidade nutricional do leite, mas também acarretar riscos à saúde (BURIN et al., 2012).

A comercialização desse alimento sem a liberação dos órgãos de vigilância responsáveis o torna impróprio para o consumo, pois não perpassa pelas etapas necessárias para sua garantia de qualidade, como a pasteurização cuja etapa visa destruir ou diminuir a presença de micro-organismos contaminantes, em especial os que oferecem riscos à saúde humana, mas sem causar grandes alterações na sua composição normal (LEITE et al., 2002; BRASIL, 2011). 
As fraudes no leite podem acontecer em qualquer uma das etapas de sua produção, sendo realizadas pelos produtores, com o intuito de entregar menos leite às indústrias, pelos caminhoneiros a mando ou não de terceiros no momento do seu transporte e na chegada as indústrias de beneficiamento (FIRMINO et al., 2010).

A adulteração mais comum e mais antiga é a adição de água, urina, soro ou outros elementos usados para aumentar o volume do leite. Novos tipos surgiram ao longo dos anos como a utilização do amido, sais e açúcares que são ditos reconstituintes da densidade, ou seja, tem a função de devolver a densidade normal ao leite. Também são adicionados elementos que visam aumentar a durabilidade do leite, pela inibição do crescimento de micro-organismos, como o formol, cloro e água oxigenada. E outros que tem a função de mascarar a acidez da fermentação microbiana, como o hidróxido de sódio, peróxido de hidrogênio e o bicarbonato de sódio (ALMEIDA, 2013).

Segundo a Instrução Normativa n 62, de 29 de dezembro de 2011, legislação vigente no Brasil que define os padrões de qualidade físico-química e microbiológica do leite pasteurizado, o mesmo não deve receber adição de nenhuma substância estranha a sua composição mesmo que não seja prejudicial à saúde humana. As amostras não devem apresentar contaminação por micro-organismos do gênero Salmonella spp. e a contaminação de coliformes termotolerantes não deve ultrapassar $4 \mathrm{NMP} / \mathrm{mL}$ (BRASIL, 2011).

Quando constatada a presença desses micro-organismos após a realização das técnicas de pasteurização, são indicativos de que houve contaminação após os processos térmicos ou de que esses foram insuficientes para sua esterilização, já que estas bactérias são sensiveis a altas temperaturas. Isso mostra também que provavelmente as boas práticas higiênico-sanitárias não foram seguidas corretamente (GILMOUR; ROWE, 1990).

Um dos principais agentes responsáveis por graves intoxicações alimentares é a bactéria entérica Salmonella spp., responsável por significantes índices de morbidade e mortalidade, tanto nos países emergentes quanto nos países desenvolvidos (SHINOHARA et al., 2008). Os principais sintomas das salmoneloses são febre, dor de cabeça, náuseas, vômitos, falta de apetite, cólicas e diarreia, que pode ter ou não sinais de sangue. Em indivíduos mais vulneráveis podem causar maior sintomatologia como desidratação, septicemia e até mesmo levar a óbito. Desta forma, torna-se evidente à importância da fiscalização (CARDOSO; CARVALHO, 2006).

Segundo Shinohara et al. (2008), os principais alimentos responsáveis pela transmissão das bactérias do gênero Salmonella são de origem animal, principalmente aves e ovos, mas também entram nesta lista a carne bovina e suína, os peixes, os frutos do mar, os laticínios como o leite e queijos oriundos de leite não pasteurizados e sorvetes. 
No Brasil, a venda de leite cru diretamente ao consumidor é vetada por lei, Decreto-lei n 923/69 (BRASIL, 1969). Apesar desta proibição, o comércio direto do leite ao consumidor ainda é uma prática comum em alguns municípios interioranos (MENDES et al., 2010; SILVA et al., 2017; SOUZA; NOGUEIRA; NUNES, 2011).

A avaliação do leite quanto a sua qualidade se faz fundamental, pois o consumo de produtos adulterados e/ou contaminados podem acarretar risco a saúde do consumidor, tanto pela presença de micro-organismos patogênicos, quanto pela presença de substâncias potencialmente toxicas.

O objetivo deste estudo foi verificar a presença de adulterantes e analisar a qualidade microbiológica de leite cru (comercializados informalmente) e leite pasteurizado comercializados informalmente, quanto a coliformes termotolerantes e Salmonella.

\section{FUNDAMENTAÇÃO TEÓRICA}

\section{LEITE}

Segundo a instrução normativa $n^{\circ} 62$ de 2011 que caracteriza e regulamenta a sua produção, o leite é o produto proveniente da ordenha completa e ininterrupta de vacas saudáveis, bem alimentadas e descansadas, realizada em condições satisfatórias de higiene (BRASIL, 2011).

Dados da Organização das Nações Unidas para Agricultura e Alimentação (FAO) relatam que, em 2010 o Brasil foi considerado o quinto pais com maior produção de leite. Desde 1974 o país vem crescendo nessa categoria em uma taxa quase constante até os dias de hoje (MAIA et al., 2013).

Desde a aprovação do Regulamento de Inspeção Industrial e Sanitária de Produtos de Origem Animal (RIISPOA) em 1952, que tornou obrigatória certas etapas na produção do leite como, a pasteurização, inspeção e carimbo do Serviço de Inspeção Federal, o país vem crescendo na sua busca por qualidade da produção, o que pode ser visto no seu crescimento dentro do mercado exterior. Este decreto também foi responsável por classificar o leite em tipos A, B e C de acordo com o tipo de ordenha, se mecânica ou manual, processamento, transporte, comercialização e a contagem bacteriana total que é a principal diferença entre as classes (VILELA et al., 2017).

No art. 543 do RIISPOA define-se como leite fraudado ou adulterado aquele que for de uma espécie e vendido como de outra, o que teve o acréscimo de água, subtração de um ou mais dos seus componentes normais e adição de elementos estranhos a sua composição como conservantes, neutralizantes da acidez e reconstituintes de densidade (BRASIL, 1952). 
A qualidade do leite tem influência direta da matéria prima recebida nas indústrias de processamento, dessa forma, as mesmas não podem reestabelecer a qualidade desse alimento. Porém existem maneiras de se adulterar o leite com o intuito na maioria das vezes de aumentar os lucros, como a adição de água e outras substâncias para aumentar o volume de leite, entregando assim maiores quantidades as indústrias, boa parte dessas fraudes são realizadas pelos produtores ainda nas fazendas, ou até mesmo durante seu transporte (FIRMINO et al., 2010).

\section{Adulterantes do leite}

\section{Reconstituíntes da densidade}

Uma das práticas mais comuns de adulteração é a adição de água ou outros elementos para o aumento de volume, isto leva a uma alteração na densidade do leite. Com a finalidade de reestabelecer a densidade padrão do produto alguns elementos podem utilizados como amiláceos, cloretos e açúcares que são conhecidos como reconstituíntes da densidade. No Brasil não é permitida a utilização de nenhum elemento estranho à composição do leite como aditivo para o seu consumo, mesmo que esses não causem prejuízo à saúde. A adição fraudulenta de água também interfere diretamente na qualidade microbiológica do leite uma vez que boa parte dos fraudadores não utiliza água tratada (FIRMINO et al., 2010; CAMPOS et al., 2011).

\section{Inibidores do crescimento bacteriano}

Outra prática comum dos fraudadores é o acréscimo de substâncias conservantes, com a finalidade de inibir ou impedir o crescimento bacteriano, já que esses micro-organismos podem causar deterioração no leite graças ao seu metabolismo. Essas substâncias normalmente são as mais baratas encontradas no mercado, como água oxigenada, água sanitária e até mesmo o formol, esses são elementos altamente prejudiciais à saúde, pois podem causar graves danos quando ingeridos em grandes quantidades e efeitos cancerígenos em pequenas doses. (CAMPOS et al., 2011).

\section{Neutralizantes da acidez}

A contaminação por substâncias alcalinas no leite pode ocorrer por duas vias, tanto pela adição intencional com o intuito de aumentar a conservação e/ou mascarar a acidez elevada; quanto por falhas na higienização, já que elementos alcalinos são usados na sanitização de equipamentos, utensílios e da própria 
estrutura física. A confirmação da presença desses elementos no leite ocorre através da viragem de cor da amostra após a adição do regente. Esses testes são de fácil realização, porém a identificação dos mesmos depende de provas específicas para cada substância o que dificulta as análises em laboratório (CAMPOS et al., 2011).

\section{Contaminação microbiológica}

As características intrínsecas ao leite bovino como o seu pH próximo da neutralidade, alto teor de gorduras, proteínas e carboidratos faz com que ele seja um meio extremamente propício ao desenvolvimento e multiplicação de diversos grupos de micro-organismos (TONINI, 2014). Organismos responsáveis por causar doenças e prejudicar a qualidade do leite estão presentes em todo o ambiente (MENEZES, 2014).

De acordo com Landgraf (1996) certos grupos de micro-organismos quando encontrados em alimentos são utilizados como indicadores de contaminação fecal. São os chamados coliformes termotolerantes, organismos responsáveis por indicar uma possível contaminação por outras bactérias que podem acelerar a deterioração do alimento ou causar doenças e também como indicativo de condições inadequadas de higiene em alguma das etapas de processamento daquele alimento.

A sobrevivência desses micro-organismos em alimentos depende tanto de certas características inerentes ao alimento como de fatores relacionados ao ambiente a que esse alimento está exposto (LANDGRAF, 1996).

Esses micro-organismos são encontrados tanto no intestino dos seres humanos como nos dos animais e podem ser disseminados através do solo, da água, de objetos, excrementos entre outros meios. Certos cuidados podem ser tomados para evitar a contaminação dos alimentos, além de medidas que quando seguidas corretamente evitam a multiplicação dos micro-organismos já presentes (MENEZES et al., 2014).

\section{MATERIAIS E MÉTODOS}

\section{COLETA DAS AMOSTRAS}

As amostras analisadas foram coletadas na qualidade de consumidor diretamente de supermercados e de vendedores informais que comercializam - leite no município de Jequié, Bahia. Para a aquisição das amostras de leite pasteurizado foi efetuado um levantamento das principais marcas de leite pasteurizado comercializados nos maiores supermercados localizados na cidade. As amostras de leite in natura foram adquiridas diretamente com indivíduos que 
comercializam informalmente esse alimento, ou seja, não possuem liberação dos órgãos de vigilância responsáveis para a comercialização do seu produto, pois não perpassam pelas etapas necessárias para garantia de qualidade.

Assim, foram selecionadas 6 amostras de leite, sendo 4 de leite in natura fornecido por vendedores informais e 2 de leite pasteurizado vendidos em supermercados. As amostras foram coletadas em 2 períodos distintos, em dias e lotes diferentes para maior confiabilidade e comprovação dos resultados, concluindo assim 12 amostras.

As amostras foram coletadas em sua embalagem original e transportadas em caixas térmicas para o laboratório de Microbiologia da Faculdade de Tecnologia e Ciências (FTC), campus Jequié. Para as análises as amostras foram homogeneizadas e divididas em dois recipientes estéreis, destinados para as análises químicas e microbiológicas respectivamente.

\section{Análises colorimétricas de adulterantes do leite}

Todos os testes foram realizados em triplicata, e com uso de controle positivo adequado a cada tipo de avaliação.

\section{Amido}

Acrescentou-se $10 \mathrm{~mL}$ de leite em tubo de ensaio, que depois foi colocado em banho-maria até ebulição durante 5 minutos, em seguida os tubos foram resfriados em água corrente e adicionado $100 \mu \mathrm{L}$ de solução de Lugol (QUEEL) (BRASIL, 2006).

\section{Cloretos}

Em um tubo de ensaio foi adicionado $10 \mathrm{~mL}$ de leite, $0,5 \mathrm{~mL}$ de solução de cromato de potássio (LabSynth) a $5 \%$ e 4,5 mL de solução de nitrato de prata (Química Moderna) a 0,1 mol/L (BRASIL, 2006).

\section{Cloro e hipocloritos}

Em tubo de ensaio adicionou-se $5 \mathrm{~mL}$ de leite e $0,5 \mathrm{~mL}$ de solução de iodeto de potássio (LabSynth) a 7,5\% seguido de agitação. Para a pesquisa da presença de hipocloritos foi adicionado ao mesmo tubo $4 \mathrm{~mL}$ de solução de ácido acético (VETEC) e colocado em banho-maria a $80^{\circ} \mathrm{C}$ por 10 minutos, a seguir fez-se o resfriamento em água corrente (BRASIL, 2017). 


\section{Hidróxido de sódio}

Acrescentou-se $5 \mathrm{ml}$ de leite e $200 \mu \mathrm{L}$ de azul de bromotimol (QUIMBRAS) a $1 \%$ em um tubo de ensaio (PEREIRA et al., 2001).

\section{Análises microbiológicas}

Pesquisa de coliformes termotolerantes

Para a determinação de coliformes termotolerantes utilizou-se a técnica de tubos múltiplos, que permite a quantificação do número mais provável de micro-organismos na amostra, pela produção ou não de gás pelas bactérias nos tubos de Durhan.

Fez-se a inoculação das amostras em tubos contendo caldo lauril sulfato triptose (KASVI), e posterior incubação dos mesmos a $36 \pm 1^{\circ} \mathrm{C}$ por 24 a 48 horas, onde a presença de coliformes foi evidenciada pela formação de gás nos tubos de Durhan, produzido pela fermentação da lactose contida no meio, constituindo assim prova presuntiva para identificação de coliformes termotolerantes. A prova confirmatória da presença ou não de coliformes se deu por meio da inoculação dos tubos positivos da etapa anterior em caldo Escherichia Coli (KASVI) e incubação dos mesmos em banho-maria a $45 \pm 1^{\circ} \mathrm{C}$ por 24 a 48 horas. A presença de gás nos tubos de Durhan indica fermentação de lactose, ou seja, presença de coliformes, já que esses meios possuem seletividade para micro-organismos desse grupo (Figura 1) (BRASIL, 2003).

Figura 1: Fluxograma da técnica de tubos múltiplos.

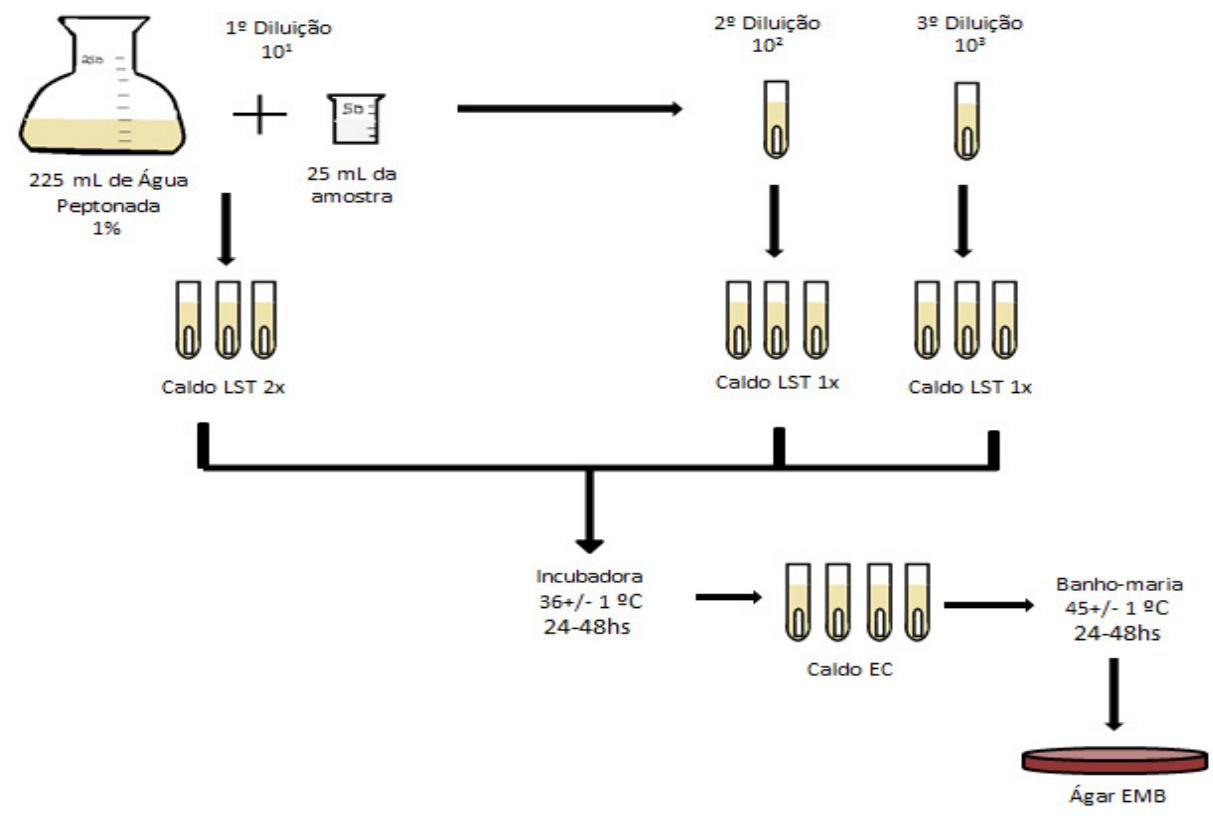

Fonte: SANTOS, 2018. 
Os resultados foram analisados em tabela do Número Mais Provável (NMP), dos tubos positivos na fase confirmatória alíquotas foram semeadas em placas de Petri contendo meio de cultura ágar eosina azul de metileno (KASVI) e incubadas a $37 \pm 11^{\circ} \mathrm{C}$ por 24 horas. E a caracterização de Escherichia coli foi evidenciada pelo crescimento de colônias com centros enegrecidos e brilho verde metálico.

\section{Pesquisa de Salmonella spp.}

Inicialmente fez-se a diluição das amostras, no qual $25 \mathrm{ml}$ de cada amostra foram transferidos para um recipiente para homogeneização contendo $225 \mathrm{~mL}$ de água peptonada tamponada (MicroMed) $1 \%$ e posterior incubação a $37^{\circ} \mathrm{C}$ por 18-20 horas, compondo a fase de pré-enriquecimento. A fase de enriquecimento seletivo consistiu-se na transferência de uma alíquota da amostra pré-enriquecida para caldo Tetrationato (Acumedia) que deve ser incubado a $37^{\circ} \pm 1^{\circ} \mathrm{C}$ por $24 \mathrm{~h}$. Em seguida, realizou-se o estriamento das amostras, o meio de cultura utilizado foi o Salmonella Shigella Ágar (KASVI), que foi incubado a $37 \pm 1^{\circ} \mathrm{C}$ por 24 horas (Figura 2).

Após o período de incubação, fez- se a leitura das placas por meio da observação de colônias, mediante as características morfológicas da Salmonella. No meio SS o crescimento de espécies de Salmonella aparece em colônias incolores com centros pretos e Shigella também aparece na forma de colônias transparentes, porém sem centros pretos.

Para a confirmação da presença de colônias de Salmonella spp. foram feitos os testes bioquímicos Ágar Tríplice açúcar ferro, que através da viragem de cor do meio de rosa para o amarelo, demonstra o crescimento de micro-organismos que utilizam os açúcares presentes no meio como fontes de energia (KASVI) e o Citrato de Simmons, utilizado para a diferenciação de micro-organismos que usam o citrato como fonte de carbono para seu metabolismo em um ambiente laboratorial (KASVI) (BRASIL, 2011).

Figura 2: Fluxograma da técnica de semeadura em placa para pesquisa de Salmonella spp.

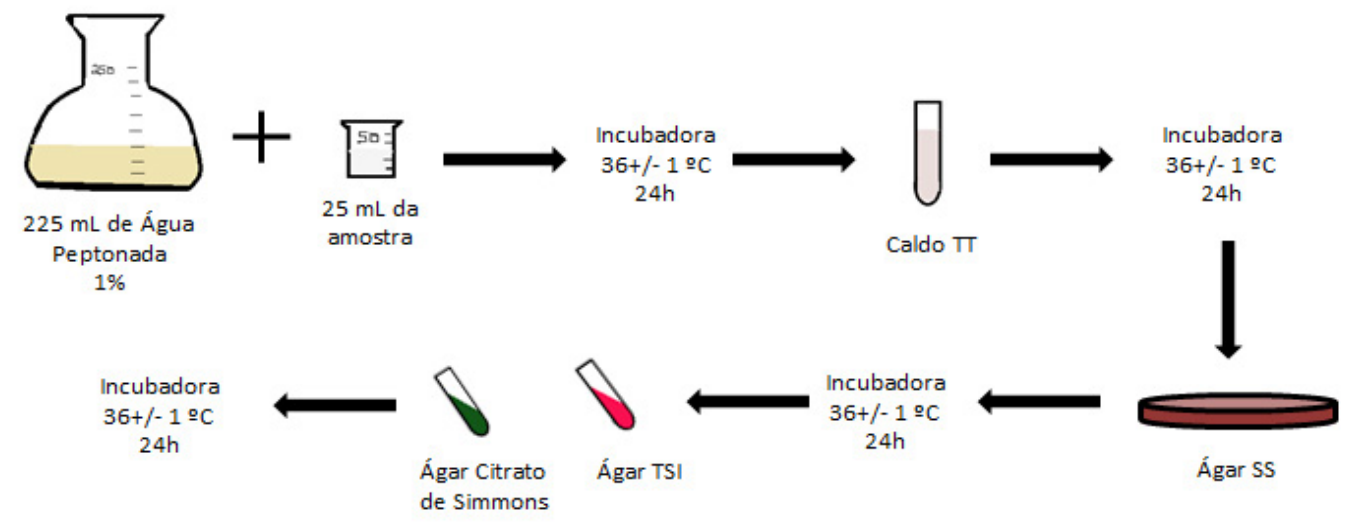

Fonte: SANTOS, 2018. 


\section{RESULTADOS E DISCUSSÃO}

\section{ADULTERANTES DO LEITE}

Em relação às análises químicas para a pesquisa de adulterantes, as amostras de leite in natura (I) e pasteurizado (II) apresentaram um aumento para taxa de cloretos em 33,3\% e 50\% respectivamente (Tabela 1). Desta forma, estas amostras não estavam de acordo com o preconizado pela instrução normativa n 76 de 2018 (BRASIL, 2018). A prova de cloretos (Figura 3) tem a finalidade de revelar se houve adição de substâncias químicas com o intuito de mascarar o acréscimo fraudulento de água, uma vez que, essas ajudam a reconstituir a densidade ou índice crioscópico do leite (ABRANTES; CAMPÊLO; SILVA, 2014; CAMPOS, 2011).

Tabela 1: Resultado das provas para pesquisa de substâncias adulterantes no leite cru e pasteurizado (Jequié-Ba).

\begin{tabular}{|c|c|c|c|c|c|}
\hline \multirow{2}{*}{$\begin{array}{l}\text { Tipos de } \\
\text { Amostras }\end{array}$} & \multirow{2}{*}{$\begin{array}{c}\text { Número de Amostras } \\
\text { Analisadas }\end{array}$} & \multicolumn{4}{|c|}{ Presença ou ausência de Substâncias Adulterantes ( $\left.\mathrm{N}^{\circ}, \%\right)$} \\
\hline & & Amido & Cloretos & Cloro & Hidróxido \\
\hline I & 8 & $0(0 \%)$ & $4(50 \%)$ & $0(0 \%)$ & $0(0 \%)$ \\
\hline ॥ & 4 & $0(0 \%)$ & $0(0 \%)$ & $0(0 \%)$ & $0(0 \%)$ \\
\hline TOTAL & 12 & $0(0 \%)$ & $4(33,3 \%)$ & $0(0 \%)$ & $0(0 \%)$ \\
\hline
\end{tabular}

I= amostra de leite in natura; II= amostra de leite pasteurizado.

Fonte: SANTOS, 2018.

Figura 3: Prova química para cloreto no leite. Em 1A e 1B amostras negativas, em 2A e 2B Amostras positivas; e em $1 \mathrm{C}$ e $2 \mathrm{C}$ controles positivos.
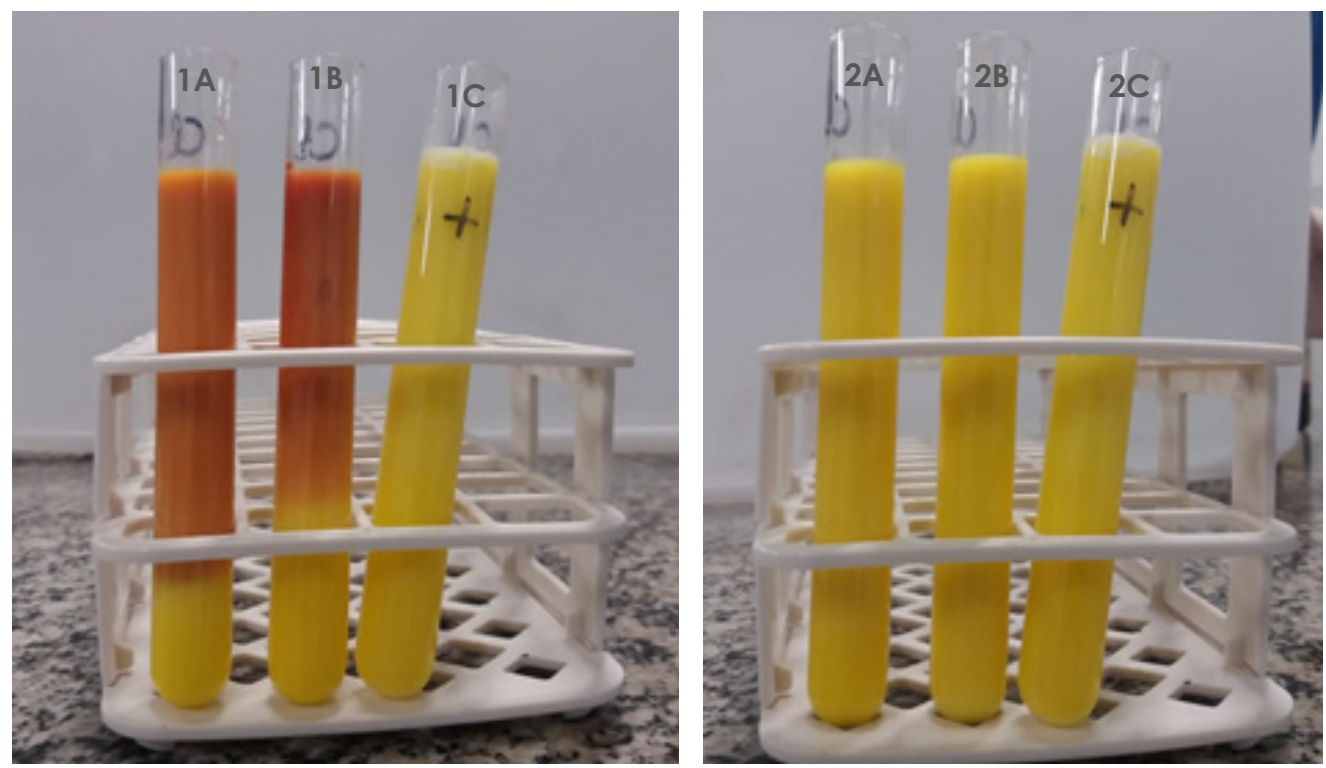

Fonte: SANTOS, 2018.

\section{INTER SCIENTIA}

REVISTA INTERSCIENTIA | V. 7 | N. 1 | P. 66-82 | JAN-JUN/2019 
Campos et al. (2011) em sua pesquisa por fraudes no leite obtiveram resultados positivos para adição de substancias neutralizantes, reconstituintes e antimicrobianas. Foi detectada a presença de bicarbonato, cloretos e sacarose, além da presença de água oxigenada em sua análise de leite tipo C do município de Brasília, corroborando parcialmente com os resultados dessa pesquisa.

Seja qual for o tipo de fraude to das tem apenas um objetivo, aumentar olucro, seja do produtor, distribuidor ou da indústria. As formas de se atingir esse objetivo são o aumento do volume, conservação do leite e o encobrimento da acidez. Porém, estas adulterações além de gerar prejuízos econômicos aos consumidores, que pagam por um produto com certas características, mas recebem um inferior, também podem gerar danos à saúde dos consumidores.

As substâncias adicionadas ao leite em sua maioria são substâncias tóxicas ao organismo humano e quando ingeridos podem provocar irritações, intoxicação aguda, e queimaduras do trato gastrointestinal. Além do que, quando ingeridos em doses frequentes e em quantidades pequenas podem ter efeitos carcinogênicos (CAMPOS et al., 2011).

Porém, os resultados não devem ser analisados de forma individual, quando há alteração em somente um padrão de normalidade não se pode caracterizar necessariamente a existência de fraude, pois diversos fatores como variação natural devido ás características fisiológicas e nutricionais inerentes ao animal interferem diretamente nos resultados obtidos.

\section{CONTAMINAÇÕES MICROBIOLÓGICAS}

Das análises quanto à contaminação por coliformes termotolerantes, $66,6 \%$ das amostras apresentaram taxas que variam de 4,3 a >110 NMP/mL (Tabela 2). Assim, estas amostras não se encontravam dentro dos padrões estabelecidos pela Agência Nacional de Vigilância Sanitária (ANVISA) instituído pela RDC n 12 de 2001 (BRASIL, 2001). Ao realizar teste confirmatório, 100\% das amostras que foram positivas para coliformes termotolerantes (Figura 4) se mostraram positivos também para crescimento Escherichia coli (Figura 5). Estes resultados podem indicar um alto nível de contaminação por patógenos fecais.

Tabela 2: Número e percentual de amostras de leite in natura e leite pasteurizado fora dos padrões para Coliformes fecais e confirmação de contaminação por E. coli

\begin{tabular}{cccc}
\hline Tipos de Amostras & Número de Amostras Analisadas & \multicolumn{2}{c}{ Amostras fora dos Padrões (No, \%) } \\
& & Coliformes Fecais & E. Coli \\
I & 8 & $6(75 \%)$ & $6(75 \%)$ \\
Total & 4 & $2(50 \%)$ & $2(50 \%)$ \\
& 12 & $8(66,6 \%)$ & $8(66,6 \%)$ \\
\hline
\end{tabular}

I: amostra de leite in natura; II= amostra de leite pasteurizado.

Fonte: SANTOS, 2018.

\section{INTER/SCIENTIA}


Figura 4: Tubos positivos para coliformes termotolerantes.

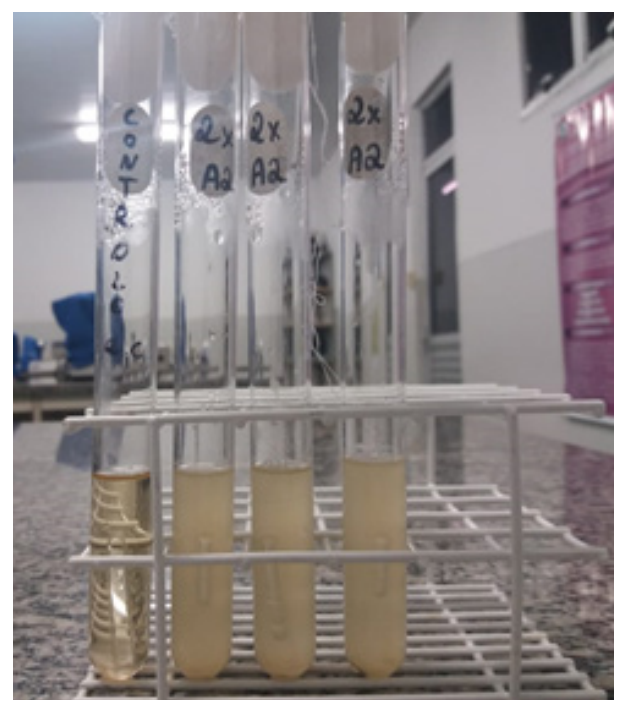

Fonte: SANTOS, 2018.
Figura 5: Placa de EMB, com crescimento positivo para E. coli.

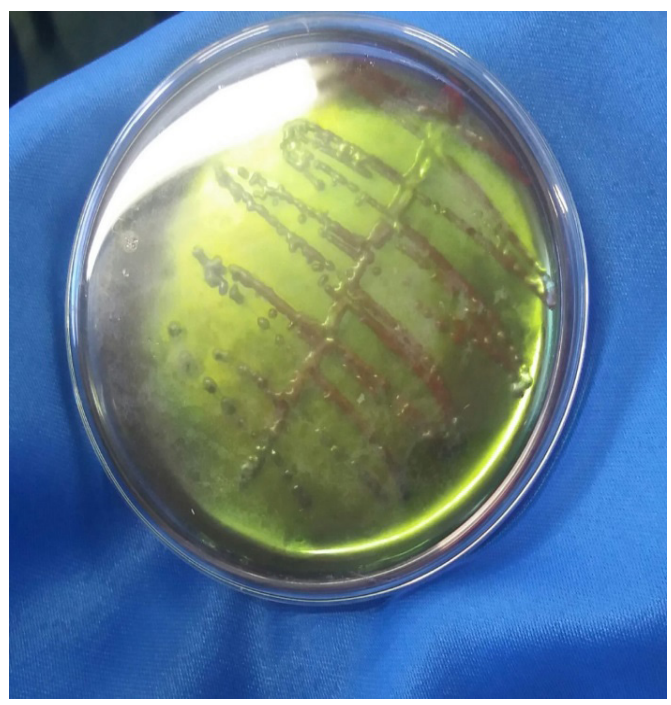

Fonte: SANTOS, 2018.

Esses dados são muito semelhantes aos de Queiroz (1995), que ao fazer uma avaliação de leite cru comercializado informalmente em dois municípios do estado de São Paulo constatou que $81,7 \%$ das amostras possuíam o NMP para coliformes termotolerantes acima do permitido. Coliformes em níveis dentro do padrão são eliminados por processos térmicos como a pasteurização. Portanto, quando presentes em alimentos que já foram processados tornam-se indicativos de inadequação ou contaminação durante ou após a realização dessa etapa (GILMOUR; ROWE, 1990).

Os coliformes termotolerantes são micro-organismos que convivem em simbiose com muitos animais de sangue quente como os bois, os gatos, os porcos assim como nos seres humanos. São excretados pelas fezes desses em grandes quantidades (MENEZES et al., 2014). Assim, o grupo coliforme quando encontrados em alimentos é utilizado como indicador ambiental de contaminação fecal (LANDGRAF, 1996).

Na pesquisa por Salmonella spp. 25\% das amostras apresentaram resultado positivo (tabela 3) (Figura 6), que foi confirmado através das provas bioquímicas. Os padrões microbiológicos usados como parâmetros para a avaliação do leite cru são os estabelecidos pelo ministério da saúde para o leite pasteurizado, pois a venda de leite in natura somente é permitida para as indústrias e não diretamente ao consumidor. 
Tabela 3: Presença de Salmonela spp. em leite cru e pasteurizado (Jequié-BA).

\begin{tabular}{cccc}
\hline Tipos de Amostras & Número de Amostras Analisadas & Presença ou ausência de Salmonella spp. \\
I & 8 & Positiva & Negativa \\
II & 4 & $3(37,5 \%)$ & $5(62,5 \%)$ \\
Total & 12 & $0(0 \%)$ & $4(100 \%)$ \\
\hline
\end{tabular}

I= amostra de leite in natura; $\|=$ amostra de leite pasteurizado.

Fonte: SANTOS, 2018.

Figura 6: Placa de ágar SS, com crescimento positivo para Salmonella.

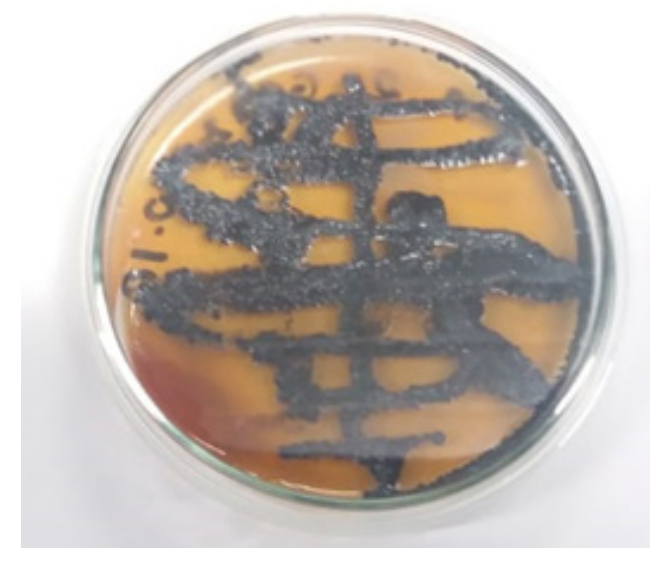

Fonte: SANTOS, 2108.

Em concordância com os resultados deste trabalho Hoffman et al. (1999), também apresentaram resultados positivos quanto a presença de Salmonella spp. em amostras comercializadas em São José do Rio preto-SP. Já autores como Macedo \& Pflanzer (2002) e Marques (2005) em suas pesquisas observaram a ausência de Salmonella spp., demonstrando a baixa ocorrência desse patógeno no leite. A preocupação com a comercialização desse alimento cru deve-se, principalmente, à falta de fiscalização do controle higiênico-sanitário, tanto dos animais quanto das instalações, da obtenção do produto e do seu transporte.

Em sua pluralidade as espécies de Salmonella são patogénicas para os humanos, e o meio mais comum de contaminação se dá pela via oral, por isso faz-se necessário avaliar a qualidade dos alimentos capazes de transmitir esse e outros micro-organismos causadores de enfermidades. Em países com baixo desenvolvimento como o Brasil, as salmoneloses são uma das principais causas de morte, por infecção alimentar (GERMANO; GERMANO, 2003).

Tendo em vista o impacto que essas contaminações podem gerar a saúde é de fundamental importância a adoção de políticas públicas que visem a capacitação dos produtores e distribuidores no que diz respeito aos cuidados com a manipulação do leite. Ações voltadas ao cuidado higiênico-sanitário durante todo o processo são essenciais para a garantia da qualidade do produto.

\section{INTER SCIENTIA}

REVISTA INTERSCIENTIA | V. 7 | N. 1 | P. 66-82 | JAN-JUN/2019 


\section{CONCLUSÃO}

A instrução normativa $n^{\circ} 76$ de 2018 proíbe a adição de qualquer elemento estranho ao leite. Nesse contexto os resultados obtidos indicam que os produtos analisados estão fora dos padrões estabelecidos pela legislação. As análises microbiológicas revelaram que $66,6 \%$ das amostras de leite apresentaram positividade para coliformes termotolerantes e $25 \%$ para Salmonella spp., estes dados demonstram uma má qualidade microbiológica do leite analisado, em desacordo com os padrões estabelecidos pela RDC no 12 de 2001.

A verificação regular do cumprimento da legislação é fundamental para garantir a qualidade do produto. Desta forma é possível evitar atos fraudulentos como a adição de substâncias estranhas à sua composição natural, além de assegurar que os padrões microbiológicos estabelecidos por lei sejam cumpridos.

\section{REFERÊNCIAS}

ALMEIDA, T.V. Detecção de adulteração em leite: análises de rotina e espectroscopia de infravermelho. 2013. Seminário (Mestrado em Ciência Animal) - Escola de Veterinária e Zootecnia da Universidade Federal de Goiás, Goiânia, 2013.

ABRANTES, M. R.; CAMPÊLO, C. S.; SILVA, J. B. A. Fraude em leite: Métodos de detecção e implicações para o consumidor. Rev. Inst. Adolfo Lutz, São Paulo, 73(3), p. 244-51, 2014.

BRASIL. Decreto-lei n 923, de 10 de outubro de 1969. Dispõe sobre a comercialização do leite cru. Diário Oficial da União, 1969.

BRASIL. Agência Nacional de Vigilância Sanitária. Resolução - RDC nº 12, de 02 de janeiro de 2001. Aprova o regulamento técnico sobre padrões microbiológicos para alimentos. Brasília, 2001.

BRASIL. Ministério da Agricultura, Pecuária e Abastecimento. Instrução Normativa n 62 , de 26 de agosto de 2003. Métodos Analíticos Oficiais para Análises Microbiológicas para Controle de Produtos de Origem Animal e Água. Departamento de Inspeção de Produto de Origem Animal. Brasília, 2003.

BRASIL. Ministério da Agricultura, Pecuária e Abastecimento. Instrução Normativa nº 68, de 12 de dezembro de 2006. Métodos Analíticos Oficiais físico-químicos para controle de leite e Produtos lácteos. Departamento de Inspeção de Produto de Origem Animal. Brasília, 2006. 
BRASIL. Ministério da Agricultura, Pecuária e Abastecimento. Instrução Normativa nº 62, de 29 de dezembro de 2011 . Regulamento Técnico de Produção, Identidade e Qualidade do Leite tipo A, o Regulamento Técnico de Identidade e Qualidade de Leite Cru Refrigerado, o Regulamento Técnico de Identidade e Qualidade de Leite Pasteurizado e o Regulamento Técnico da Coleta de Leite Cru Refrigerado e seu Transporte a Granel. Departamento de Inspeção de Produto de Origem Animal. Brasília, 2011.

BRASIL. Ministério da Agricultura, Pecuária e Abastecimento. Secretaria de Defesa Agropecuária. Manual de Métodos oficiais para Análise de Alimentos de origem animal. Brasília: MAPA, 2017.

BRASIL. Ministério da Agricultura, Pecuária e Abastecimento. Instrução normativa nº 76, de 26 de novembro de 2018. Regulamentos Técnicos que fixam a identidade e as características de qualidade que devem apresentar o leite cru refrigerado, o leite pasteurizado e o leiłe pasteurizado tipo A. Diário Oficial da União, Brasília, 2018.

BRASIL. Decreto $n^{\circ} 30.691$, de 29 de março de 1952. Regulamento da inspeção industrial e sanitária de produtos de origem animal. Disponível em: http://www. agricultura.gov.br/assuntos/sustentabilidade/bem- estar-animal/arquivos/arquivoslegislacao/decreto-30691-de- 1952.pdf. Acesso em: 24 de Novembro de 2018.

BRASIL. Secretaria de Vigilância em Saúde, normas e manuais técnicos. Manual técnico de diagnóstico laboratorial de salmonella spp. Brasília: Editora do Ministério da Saúde, 2011.

BURIN, A. S., et al. Avaliação da Qualidade Microbiológica do Leite Pasteurizado Comercializado em Apucarana-PR e Região. F@pciência, Apucarana-PR, v. 9, p. 30-41, 2012.

CAMPOS, A. A. R., et al. Avaliação físico-química e pesquisa de fraudes em leite pasteurizado integral tipo c produzido na região de Brasília, distrito federal. Rev. Inst. Latic. Cândido Tostes, Brasília, v. 66, n. 379, p.30-34, Mar./Abr., 2011.

CARDOSO, T. G.; CARVALHO, V. M. Toxifecção alimentar por Salmonella spp. Rev. Inst. Ciênc. Saúde, v. 24, n. 2, p. 95-101, 2006.

CITADIN, A. S., et al. Qualidade microbiológica de leite cru refrigerado e fatores associados. Revista Brasileira Saúde Produção Animal, [s. I.], v.10, n.1, p.52-59, Jan./ Mar., 2009. DOl: http://dx.doi.org/10.18378/rvads.v13i1.5369

FIRMINO, F. C., et al. Detecção de fraudes em leite cru dos tanques de expansão da região de rio pomba, minas gerais. Rev. Inst. Latic. Cândido Tostes, Brasília, v. 65, n. 376, p. 5-11, Set/Out, 2010. 
GERMANO, P.M.L.; GERMANO, M.I.S. Higiene e vigilância sanitária de alimentos. São Paulo: Varela, 2003.

GILMOUR, A.; ROWE, M.T. Micro-organisms associated with milk. Tradução: ROBINSON, RK Microbiologia leiteira. A Microbiologia do leite, 2. ed., Londres: Elsevier, v. 2, p. 3775,1990

HOFFMAN, F. L. et al. Microbiologia do leite pasteurizado tipo C, comercializado na região de São José do Rio Preto-SP. Revista Higiene Alimentar, São Paulo, v. 13, n. 65, p. $55,1999$.

LANDGRAF, M. Microrganismos Indicadores. São Paulo: Atheneu, cap. 3, p. 27-31, 1996.

LEITE, C.C., et al. Qualidade bacteriológica do leite integral (tipo C) comercializado em Salvador - Bahia. Revista Brasileira Saúde Produção Animal, [s. I.], v. 3, n. 1, p.2125, 2002.

MACEDO, R. E. F.; PFLANZER JR, S. B. Avaliação microbiológica do leite pasteurizado tipo "C" comercializado na região metropolitana de Curitiba. In: Simpósio latino americano de ciência de alimentos, 5., 2003, Campinas. Anais [...]. Campinas, 2003.

MAIA, G. B. S., et al. Produção Leiteira no Brasil. Rio de janeiro: BNDES, p. 371-398, Mar., 2013.

MARQUES, M. S. et al. Avaliação da qualidade microbiológica do leite pasteurizado tipo c processado no estado de Goiás. In: CONGRESSO LATINO- AMERICANO E VII BRASILEIRO DE HIGIENISTAS DE ALIMENTOS, 2., 2005, Búzios. Anais [...]. Búzios, 2005, v. 19, n. 130.

MENDES, C. V. et al. Análises físico-químicas e pesquisa de fraude no leite informal comercializado no município de Mossoró, RN. Rev. Ci. Anim. Bras., Goiânia, v. 11, n. 2, p. 349-356, 2010.

MENEZES, M.F.C., et al. Microbiota e conservação do leite. REGET- Revista eletrônica em gestão, educação e tecnologia ambiental, Santa Maria, v. 18, n. 5, p. 76-89, 2014.

PEREIRA, D. B. C. Físico-química do leite: Métodos analíticos. Juiz de Fora: Templo Gráfica e Editora. 2 ed., v. 01, p. 234, 2001.

QUEIROZ, J.C. Avaliação sanitária do leite cru distribuído nos Municípios de Juquitiba e Itapecerica da Serra. 1995. Tese (Doutorado) - Faculdade de Saúde Pública da USP, São Paulo, 1995. 
SHINOHARA, N.K.S. et al. Salmonella spp. Importante agente patogênico veiculado em alimentos. Ciência \& Saúde Coletiva, vol.13, n.5, p.1675-1683, 2008.

SILVA, G. W. N. et al. Avaliação físico-química de leite in natura comercializado informalmente no sertão paraibano. Rev. Principia - divulgação científica e tecnológica do IFPB, João Pessoa, n.35, 2017.

SOUZA, A. H. P. et al. Avaliação Físico- Química do leite UHT e pasteurizado comercializado na cidade de Londrina- PR. Rev. Brasileira de pesquisa em Alimentos, [s. I.], v. 1, n. 1, p. 39-42, 2010.

SOUZA, F. M.; NOGUEIRA, M. S.; NUNES, F. C. Qualidade microbiológica do leite cru comercializado informalmente na cidade de areia-PB. Rev. Agropecuária Técnica, [s. I.], v. 32, n. 1, p 168-171, 2011

TONINI, C. B. Avaliação da qualidade do leite e caracterização de laticínios do estado do Espírito Santo. 2014. Dissertação (Mestrado) - Universidade Federal do Espírito Santo. Alegre, 2014.

VILELA, D., et al. A evolução do leite no Brasil em cinco décadas. Revista de Politica Agrícola, Brasil, v. 26, n.1, 2017.

Recebido em: 17/04/2019.

Aceito em: 10/06/2019. 